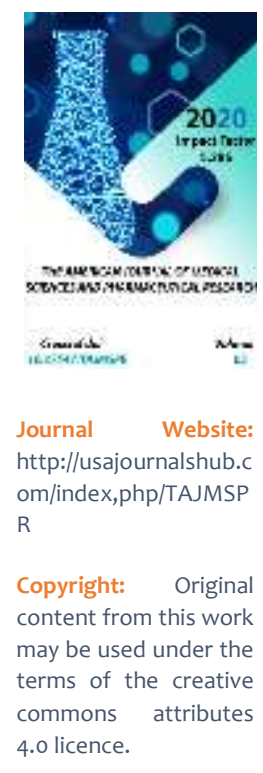

\title{
Neuroses And The Factors Which Contribute To It
}

\author{
Shukurov Sherzod Shuxratovich \\ Samarkand State Medical Institute Assistant Of The Department Of Pediatric Dentistry, \\ Samarkand Region, Uzbekistan
}

Abdisayitov Shaxzod Musurmonovich

Samarkand State Medical Institute Clinical Resident Of The Department Of Pediatric

Dentistry, Samarkand Region, Uzbekistan

Norbekov Laziz Shodiyorovich

Samarkand State Medical Institute Clinical Resident Of The Department Of Pediatric

Dentistry, Samarkand Region, Uzbekistan

\section{ABSTRACT}

Neuroses are psychogenic disorders that develop as a result of long-term exposure to a traumatic event with low intensity and sharpness. In these cases, there is usually talked of disagreements in the family, production, and work community, which are not even perceived by the patient as a factor of emotional trauma. The depth of mental disorders is relatively low in neuroses - there are no deep disturbances of thinking, cognition and consciousness, and a critical attitude to others and one's own state is preserved. The article looks into the neurosis and its causes and correlation with other illnesses.

\section{KEYWORDS}

Neurology, neuroses, neurasthenia, sleeps disorders, depression, and symptom.

\section{INTRODUCTION}

Neurosis Clinic

Neuroses are often caused by a conflict situation, along with somatic illness, severe fatigue, and other additional detrimental factors, and although they are not a direct cause of the disease, they are of great pathogen etic importance. Also, some congenital constitutional features are important and determine the frequency, severity, and duration of neurotic reactions in a number of individuals. In the neurosis clinic, there are mainly vegetative, somatic, and effective disorders that do not cause obvious behavioral disorders and are relatively easy to treat. In some cases, the neurosis can progress to a person's neurotic development over a period of years after the traumatic event. Neuroses are divided into neurasthenia (a functional disorder of the nervous system as a result of exhaustion and extreme fatigue, a type of neurosis), hysteria (a neurological 
disease of a functional nature of the nervous system, a form of mental disorder) and sticky neurosis.

Neurasthenia often develops in people who are prone to fatigue and mood swings. These features are also observed in normal cases in such individuals. Under the influence of traumatic events, they develop a neurotic reaction in the form of asthenic (fatigue, general weakness) syndrome. Decreased ability to work and appetite, headache, insomnia and weakness, drowsiness. Attention concentration is impaired in patients. They are easily upset and impatient. Various autonomic disorders are observed, including high blood pressure, tachycardia, profuse sweating, tremor, and often sexual dysfunction. Due to fatigue, the threshold for movement is high. Patients become irritable (irritable weakness), easily agitated, and prone to frequent mood swings. In this case we are talking about a hypertensive form of neurasthenia. If fatigue, apathy, and lethargy come to the fore in the clinic, it is called a hypotensive form.

The concept of 'neurosis' was introduced into medicine in 1776 by the Scottish physician William Cullen. The meaning of the term has been revisited many times, but so far there is no universally accepted definition. It should be noted that in medicine and biology, various functional disorders of higher nervous activity are also called "neurosis". The term "neurosis" is not currently used by the professional psychiatric community in the United States. The "neuroses" section was abolished in the 1980 DSM-III third edition of the American Diagnostic and Statistical Manual of Mental Disorders. For example, dysthymic disorder was replaced by depressive neurosis, obsessive-compulsive disorder was replaced by obsessive-compulsive disorder, and hypochondria were replaced by hypochondriac neurosis.

\section{CAUSES AND MECHANISMS OF NEUROSE DEVELOPIMENT}

In the framework of his physiological theory, I. P. Pavlov defined neurosis as a chronic longterm disorder of higher nervous activity as a result of overexertion in the cerebral cortex due to inadequate force and the influence of external stimuli. In the early twentieth century, the use of the clinical term "neurosis" not only in humans but also in animals led to much controversy. Psychoanalytic theories represent neurosis and its symptoms mainly as a result of deep psychological conflict. It is assumed that such a conflict is formed in the context of longlasting social conditions that prevent a person from meeting his basic needs and threaten his future, which a person struggles with but cannot overcome. Sigmund Freud saw such conflicts in the fundamental opposition to the suppression of Id's instinctive demands by the Super-Ego, which implies morality and norms in society. Karen Horn believes that the fundamental conflict of neurosis is the result of a conflict between a person's inconsistent defensive tendencies. In order to protect against uncomfortable social factors such as humiliation, social isolation, absolute controlling love of parents, carelessness and aggression, the child develops protection methods based on 'towards people', 'against people' and 'away from people'.

Moving towards people basically means submission, love, and protection. Acts against people represent the pursuit of power, fame, recognition, success, strength, and the struggle for life. Moving away from people represents the need for independence, freedom, freedom from people. The neurotic 
patient is prone to all three tendencies at the same time, but one of them is predominant, so the superior neurotic can be classified into 'submissive', 'aggressive' and 'separated' types. Karen Horn has paid close attention to the issues that have caused the conflict between defensive tendencies. In general, today, both psychological factors (characteristics of the individual, the conditions of his maturity and upbringing, the conditions of social relations, the degree of aspiration) and biological factors (certain neurotransmitters or neurophysiological factors that make them vulnerable to certain psychogenic effects) functional deficiency of the systems) are considered as factors contributing to the development of neurosis.

\section{DISTRIBUTION CRITERIA}

The main criteria for distinguishing neurotic disorders from mental disorders in general are:

The leading role of psychogenic factors in the onset and decompensating of painful manifestations;

Functional (reversible) nature of mental disorder;

Psychotic symptoms, personality changes, lack of mental retardation;

The egoistic nature of psychopathological manifestations, as well as the critical attitude of patients to their own condition.

\section{SYMPOMS AND SYMPTOMS OF NEUROSIS}

\section{SPIRITUAL SYMPTOMS}

Emotional depression (often for no apparent reason); Hesitation; Social communication problems; Inadequate self-esteem: low or excessive; Frequent anxiety, fear, "anxious expectations", phobias; panic attacks, panic disorders; Uncertainty or contradictions of the value system, life desires and preferences, opinions about oneself, others and life in general. Cynicism is often noted; Mood swings, frequent and sudden fluctuations; Irritability (neurasthenia); Hypersensitivity to stress People react to an insignificant stressful event with frustration or aggression; Crying; Depression, weakness; Anxiety; Too much focus on the psych traumatic situation; Getting tired quickly when you try to work - memory, attention and thinking skills are reduced; Sensitivity to loud noises, bright light, temperature changes; Excessive agitation makes it difficult to fall asleep; sleep is shallow, restless, restless; drowsiness is often observed in the morning.

\section{PHYSICAL SYMPTOMS}

Headache, heartache, abdominal pain.

Frequent feeling of fatigue, increased fatigue, general decrease in ability to work.

Anxiety, dizziness and darkening of the eyes due to low blood pressure.

Disorders of the vestibular apparatus: difficulty maintaining balance, dizziness.

Loss of appetite (overeating or malnutrition, feeling hungry, but getting full quickly while eating).

Sleep disorders (insomnia): difficulty falling asleep, waking up early, waking up at night, lack of feeling refreshed after sleep, having nightmares.

The psychological experience of physical pain (psychiatry) is an overestimation of one's own health that leads to hypochondria.

Vegetative disorders: excessive sweating, palpitations, changes in blood pressure, gastric 
disorders, cough, frequent urination, fecal fluid.

Sometimes there is a decrease in libido and erection.

\section{RELATIONSHIP OF NEUROSIS WITH OTHER DISEASES AND SYMPTOMS}

\section{HEADACHE}

Headaches occur in a variety of mental states and illnesses. It usually occurs when there is emotional stress or suppression of one's emotions (such as anger). Also, headaches can be hallucinatory.

\section{VEGETOTOMIR DYSTONIA}

Vegetotomy dystonia is a disorder of the autonomic nervous system. Unlike the somatic nervous system, which controls the mind and controls the muscles, the autonomic nervous system works automatically and keeps the organs and systems of the body functioning. When there is danger, the autonomic nervous system mobilizes the body's forces to overcome the risk (for example, increase blood pressure). If a person is unable to actively respond to a situation that is often perceived as dangerous (e.g., due to social factors) and is forced to suppress his or her anxiety, as well as many non-dangerous situations make him or her feel fearful ( or if he is suffering from panic attacks), the autonomic nervous system begins to malfunction, errors accumulate and loss of balance occurs, which leads to disturbances in the function of various organs, in addition to the direct symptoms of VTD. PANIC DISORDERS, PHOBIA, FEELING OF ANXIETY

Various anxiety disorders (panic attacks, phobias, constant anxiety) are usually accompanied by neurosis.

\section{TREATMENT OF NEUROSIS}

There are many treatments and theories for neurosis. Treatment of neurosis is based on psychotherapy and drug therapy using antidepressants and tranquilizers. The main method of treatment of neurosis and neurotic reactions is psychotherapy. There are many types of psychotherapy available today. They can be pathogenic (affecting the causes of neurosis and the process of its retention in a person) and symptomatic or auxiliary (they are effective only in combination with pathogenic methods, they themselves have only a temporary effect that relieves symptoms).

Pathogenetic methods include psychodynamic, existential, interpersonal, cognitive, systemic, integrative, gestalt therapy.

Symptomatic methods include behavioral, hypnosis, body-oriented, exposure therapy, breathing exercises, art therapy, music therapy, and more.

Neurosis is a reversible condition that responds well to psychotherapeutic treatment. Drug therapy is only a catalyst for the psychotherapeutic process and is in no way considered the primary form of treatment for neurosis. In rare cases, independent resolution of neurosis as a result of the growth of a person's personality, loss of significance of the conflict situation, return to the previous way of life, etc. is also reported.

Cognitive-behavioral therapy (CCT) and SQUSI (selective serotonin reuptake inhibitors) or clomipramine antidepressants are recommended as the primary treatment for obsessive-compulsive disorder. In addition to cognitive-behavioral therapy, psychodynamic therapy or psychoanalysis are also used, but 
their effectiveness has been little proven, as opposed to the effectiveness of CCT. CCT is the only type of psychotherapy that has been proven in controlled studies to be effective in obsessive-compulsive disorder.

\section{CONCLUSION}

Adaptive training is used in the cognitive treatment of obsessive-compulsive disorder - a technique in which the therapist tries to evoke recurring thoughts in the patient, with the result that such thoughts lose the importance of risk to the patient and lead to a decrease in anxiety. . A covert technique of prevention of response is also used: therapists teach patients to distract or avoid established ideas that may occur during adaptive training. According to the proponents of cognitive theory, such a disorder is characterized by the presence of unpleasant, unnecessary thoughts in the person.

\section{REFERENCES}

1. Elizarova V. M., Drobotoko L. N., Strakhova S. Yu. / / Lech. doctor. - 2000. - no. 8. - P. 2729.

2. Isakov V. A., Rybalkin S. B., Romantsov M. $G$. herpesvirus infection: a manual for doctors. - SPb., 2006. - 95 p.

3. Levonchuk E. A. herpetic infection of a polostyrta // Tell lies. dentistry. - 2005. №1. - C.19-23

4. Looker, KJ; Garnett, GP; Schmid, GP (October 2008). "An estimate of the global prevalence and incidence of herpes simplex virus type 2 infection". Bulletin of the World Health Organization. 86 (10): 805-12, A.

5. Dickerson FB, Boronow JJ, Stallings $C$, et al. (March 2004). "Infection with herpes simplex virus type 1 is associated with cognitive deficits in bipolar disorder". Biol. Psychiatry. 55 (6): 588-93.

6. Rapini, Ronald P.; Bolognia, Jean L.; Jorizzo, Joseph L. (2007). Dermatology: 2Volume Set. St. Louis: Mosby. ISBN 978-14160-2999

7. Baratova sh. N., Rakhimberdiev R. A., Shamsiev R. A. "Features of the course and diagnosis of dental caries in children of primary school age". Achievements of science and education-scientific and methodological journal, 2020, no. 1 (55), pp. $83-88$

8. Ubaidullaeva M. A., R. A. Rahimberdiev, Shamsiev.And. "Hygienic care of the oral cavity in children of early age". Achievements of science and educationscientific and methodological journal, 2020, no. 1 (55), pp. 88-94

9. Baratova sh. N., Rakhimberdiev R. A., Shamsiev R. A. "Prevention of permanent dental caries in children of primary school age". Achievements of science and education-scientific and methodological journal, 2020, no. 4 (58), pp. 67-75 